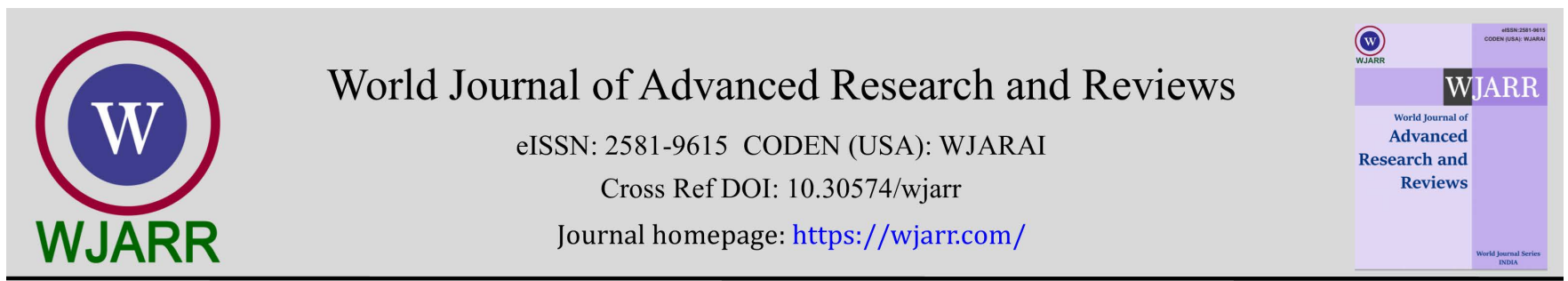

(RESEARCH ARTiClE)

\title{
Enterobacter Cloacae: The association of antibiotic resistance, integron class I and carbapenemase genes
}

\author{
Ahmed Ali Mhawesh *, Reem Naeem Ibraheem and Tamara Husham Zedan \\ Dept. of Med. and Mol. Biotech., College of Biotechnology, Al-Nahrain University, Baghdad, Iraq.
}

World Journal of Advanced Research and Reviews, 2021, 12(02), 549-554

Publication history: Received on 16 September 2021; revised on 23 November 2021; accepted on 25 November 2021

Article DOI: https://doi.org/10.30574/wjarr.2021.12.2.0464

\begin{abstract}
The opportunistic pathogen, E. Cloacae has been reported to carry carbapenemas genes worldwide. Our objective was assessing the association of antibiotic resistance, integron class I and carbapenemase genes among E. Cloacae. Herein, 200 E. Cloacae were collected and identified. The antibiotic resistance of them was evaluated using Kirby Bauer method. The existence of class I integron, carbapenemase genes was investigated using polymerase chain reaction (PCR). Of the 200 E. Cloacae isolates collected, 120 isolates (60\%) were from male and 80 isolates (40\%) were from females. Of them, 110 isolates (55\%) showed a pattern of MDR phenotype. Of these, 18 isolates (9\%) showed resistance to imipenem. Based on PCR test, 134 isolates (67\%) had class I integrons. Also, out of 110 MDR isolates, 52 isolates (72\%) were positive in terms of the presence of class I integrons. Isolates with integrons were mostly from urinary (61\%) and blood (44\%) and from ICU settings (46\%) and inpatients (38\%). A significant relationship was observed between the presence of integron and resistance to ciprofloxacin, imipenem, meropenem, and norfloxacin antibiotics. The prevalence of blaIMP, blaOXA-48 were $18 \%$ and $4 \%$, respectively, but none of other carbapenemase genes were detected. The existence of class I integron was high among E. Cloacae from Baghdad city. The carriage of genes resistance to carbapenems were significantly associated to the class I integrin.
\end{abstract}

Keywords: Enterobacter Cloacae; Antibiotic resistance; Integron class I; Carbapenemase genes

\section{Introduction}

Enterobacter species from members of the Enterobacteriaceae family involved in the development of various clinical infections, especially in hospital settings, and are currently one of the major causative agents of nosocomial infections. Enterobacter Cloacae (E. Cloacae) are involved in the development of diseases such as pneumonia and skin, lower respiratory tract, soft tissue, blood and urinary tract infections [1-3]. In recent years, the emergence and spread of highly drug-resistant strains of these species are of great concern.

There have been many reports of the presence of Enterobacter species with multiple drug resistance (MDR) patterns in the clinical wards of hospitals around the world [4-6]. This bacterium is resistant to antimicrobial drugs through a variety of mechanisms, including changes in the cell permeability to drugs, the efflux pump, the receptor modification for drugs, and the drug destroying enzymes [7,8]. The genes encoding these enzymes are either chromosomal in origin or released by other transferable genetic elements (TGEs) such as plasmids, transposons, and integrons. Integrons are elements that can be located in plasmids, chromosomes, or transposons $[9,10]$. These elements are among the factors involved in the development of MDR and, like plasmids and transposons, are part of the TGEs in the acquisition and dissemination of resistance factors [11]. In total, integrons absorb gene cassettes that contain one or more genes (often drug resistance genes) with a conserved locus.

\footnotetext{
${ }^{*}$ Corresponding author: Ahmed Ali Mhawesh

Dept. of Med. and Mol. Biotech., College of Biotechnology, Al-Nahrain University, Baghdad, Iraq.

Copyright (C) 2021 Author(s) retain the copyright of this article. This article is published under the terms of the Creative Commons Attribution Liscense 4.0.
} 
More than 60 different gene cassettes have been identified in the integration group that make them resistant to important antibiotics such as aminoglycosides, penicillins, cephalosporins, carbapenemas, trimethoprim, rifampine, erythromycin, chloramphenicol and quaternary ammonium compounds $[3,4,6]$.

Some studies have reported integrons containing more than one gene cassette that facilitate bacterial isolates to develop to MDR phenotype. The class I integration is one of the most important in the transfer of drug resistance genes. Due to the rapid spread of these genes among other species, identifying the presence of these integrons can provide advantageous information about the prevalence of resistant strains of Enterobacter spp, and how to develop it [7-10]. In the last two decades, Enterobacter species with a pattern of MDR have increased significantly in hospital settings and have caused many problems for physicians and infection control specialists. The aim of this study was to determine the relationship between the presence of class I integrons and different drug resistance patterns and carbapenemase genes in E. Cloacae.

\section{Material and methods}

In this analytical study, a total of 200 clinical isolates of E. Cloacae were collected from different wards of Baghdad hospitals from May 2018 to October 2020. Bacterial isolates were from various clinical specimens including blood, urine and urinary catheters, trachea, wound, sputum, bronchoalveolar lavage and cerebrospinal fluid and from patients admitted to intensive care units, intrauterine and orthopedic wards. The collected samples were cultured on blood agar medium (Merk, Germany) and eosin methylene blue and sent to the laboratory for identification. Then, using standard laboratory tests (microbiology and biochemistry) related to the identification of Enterobacter species were identified as follows: Gram staining, oxidase tests, production of indole, urea hydrolysis, motility, Citrate (culture on Simon Citrate medium), culture on Kligler Iron Agar media (KIA, (11) Methyl Red and Voges Prosquare (VP-MR) tests. Moreover the hsp60 species specific gene was amplified using Forward: 5'- AGAAGAGAGGCGTGGTTGC-3' and Reverese: 5'ATGCATTCGGTGGTGATCATCAG-3' primers. Bacteria isolated after diagnosis on the surface of the test. \% Glycerol was stored at $-80^{\circ} \mathrm{C}$ until further testing.

\subsection{Antibiotic susceptibility}

Antibiotic susceptibility patterns of all isolates was performed according to CLSI 2020 and use the following discs: gentamicin, tobramycin, ticarcillin- clavulanic acid, carbenicillin, ofloxacin, cefotaxime, ceftazidime, imipenem, meropenem, aztreonam, levofloxacin, trimethoprim, ciprofloxacin and piperacillin-tazobactam. For this purpose, first the Mueller Hinton Agar medium (pH 7.2 to 7.4, Merk, Germany) was used. The standard microbial suspension was then prepared on a half-McFarlane turbidity. They were incubated for 24 hours at $35{ }^{\circ} \mathrm{C}$ and then the results were recorded according to the instructions. Antibiotic discs were purchased from MAST UK. Escherichia coli strain ATCC 25922 was used to control the test.

\subsection{Polymerase chain reaction}

To determine the prevalence of class I integron, a polymerase chain reaction (PCR) test was used. In this method, a primer for integron class I gene, IntF, 5'-ATCATCGTCGTAGAGACGTCGG IntR, 5'-GTCGACGT, 5'-GTCGACGT was used. Finally, electrophoresis of the products on 1\% agarose gel was determined. The DNA extraction of all samples was performed using boiling method. To ensure the existence of DNA, the nanodrop device was used at two wavelengths of 260 and $280 \mathrm{~nm}$. The PCR reaction was performed in a total volume of $25 \mu \mathrm{l}$ and consisted of the following materials: $200 \mu \mathrm{mol} d \mathrm{dTP}, 10$ picomoles per $1 \mathrm{ml}$ of primer, $\mathrm{MgCl} 2,0.5 \mathrm{U}$ of Taq polymerase enzyme and 50 ng of template DNA.

Amplification of the class I integron gene was performed under the following conditions using a thermocycling device (biosystems, US). Primary denaturation temperature $\left(94^{\circ} \mathrm{C}\right.$ for for 5 minutes), 35 cycles of $94^{\circ} \mathrm{C}$ for 3 min, the annealing temperature $\left(55^{\circ} \mathrm{C}\right.$ for $\left.30 \mathrm{sec}\right)$ and the amplification temperature $\left(72^{\circ} \mathrm{C}\right.$ for $\left.1 \mathrm{~min}\right)$ and at the end the final amplification temperature $\left(72^{\circ} \mathrm{C}\right.$ for $\left.10 \mathrm{~min}\right)$.

The existence of blaIMP, blaOXA-48, blaVIM, blaNDM and blaKPC genes was investigated by PCR (table1). 
Table 1 Sequence of primers of carbapenemase genes

\begin{tabular}{|c|c|c|c|c|}
\hline Primers & Sequence 5'----3' & Annealing Temp. & Amplicon size (bp) & Reference \\
\hline bla $_{\mathrm{KPC}-2}$ & $\begin{array}{l}\text { F: TTGCCGGTCGTGTTTCCCTTTAGC } \\
\text { R: GGCCGCCGTGCAATACAGTGATA }\end{array}$ & 64 & 282 & \multirow{4}{*}[12,13]{} \\
\hline blaviм & $\begin{array}{l}\text { F: CATTGTCCGTGATGGTGATGAGT } \\
\text { R: GCGTGTCGACGGTGATGC }\end{array}$ & 61 & 205 & \\
\hline bla $_{\text {OХA-48 }}$ & $\begin{array}{l}\text { F: CGCCCGCGTCGACGTTCAAGAT } \\
\text { R: TCGGCCAGCAGCGGATAGGACAC }\end{array}$ & 65 & 484 & \\
\hline bla $_{\mathrm{NDM} 1}$ & $\begin{array}{l}\text { F: CGCACCTCATGTTTGAATTCGCC } \\
\text { R: GTCGCAAAGCCCAGCTTCGC }\end{array}$ & 61 & 1015 & \\
\hline blaIMP $_{1}$ & $\begin{array}{l}\text { F: GGGTGGGGCGTTGTTCCTA } \\
\text { R: TCTATTCCGCCCGTGCTGTC }\end{array}$ & 62 & 198 & \\
\hline
\end{tabular}

Data were analyzed using SPSS 20 software and Chi-square and Fisher's exact tests. In the analysis of the results, groups with moderate and complete resistance were integrated and $\mathrm{P}<0.05$ was considered statistically significant.

\section{Results}

Of the 200 E. Cloacae isolates collected, 120 isolates (60\%) were from male and 80 isolates (40\%) were from females. The mean age of patients was $51 \pm 5$ years (age range 14 to 83 years). Most isolates were collected from urine $(82,41 \%)$ and blood $(50,25 \%)$ and from patients admitted to ICU settings (88 patients, $44 \%$ ) and internal ward (66 patients, $33 \%)$.

Table 2 The antibiotic resistance pattern of E. Cloacae isolates

\begin{tabular}{|c|c|c|c|}
\hline Disk/Resistance (N=200) & Susceptibility \% & Intermediate \% & Resistance \% \\
\hline CAZ & 34 & 0.0 & 66 \\
\hline CTX & 36 & 0.0 & 64 \\
\hline CN & 31 & 5 & 61 \\
\hline AMC & 37 & 8 & 55 \\
\hline IPM & 52 & 8 & 40 \\
\hline MEM & 53 & 9 & 38 \\
\hline PITZ & 68 & 2 & 30 \\
\hline TI-CLA & 63 & 0.0 & 37 \\
\hline OFX & 46 & 3 & 51 \\
\hline GN & 58 & 4 & 38 \\
\hline AZ & 26 & 4 & 70 \\
\hline TOB & 44 & 0.0 & 56 \\
\hline CP & 29 & 2 & 69 \\
\hline TMP & 47 & 3 & 50 \\
\hline LFX & 31 & 4 & 65 \\
\hline
\end{tabular}


Based on the results of antibiotic susceptibility test, 110 isolates (55\%) showed a pattern of MDR (in the classes of betalactam, aminoglycoside and quinolone antibiotic drugs) as shown in table 2. Of these, 18 isolates (9\%) showed resistance to imipenem, 14 isolates (7\%) showed moderate resistance and 168 isolates (84\%) were susceptible. It was also found that among MDR-E. Cloacae, 110 isolates (55\%) were sensitive to meropenem and 6 isolates (3\%) showed intermediate resistance.

Based on PCR test, 134 isolates (67\%) had class I integrons. Also, out of 110 MDR isolates, 52 isolates (72\%) were positive in terms of the presence of class I integrons. Isolates with integrons were mostly from urinary (61\%) and blood (44\%) and from ICU settings (46\%) and inpatients (38\%). No significant correlation between integrons class I and MDR pattern and between class I integrons and resistance to antibiotics gentamicin, Amoxicillin-clavulanic acid, cefotaxime, ceftriaxone, ceftazidime, cefpodoxime, aztreonam, piperacillin, trimethoprim was observed. But a significant relationship was observed between the presence of integron and resistance to ciprofloxacin, imipenem, meropenem, and norfloxacin antibiotics.

The prevalence of blaıмp, blaoxA-48 were $18 \%$ and $4 \%$, respectively, but none of other carbapenemase genes were detected. The relation of class I integron and carbapenemase genes has been shown in table 3 and figure 1.

Table 3 The relation of class I integron and carbapenemase genes

\begin{tabular}{|l|c|c|l|}
\hline Integron & blaimp $(\mathbf{n = 3 8})$ & blaoxa48 $(\mathbf{n = 8})$ & Resistance profile \\
\hline Class I $(\mathrm{n}=134)$ & $34 \%$ & $6 \%$ & CP, IMP, MER, NOR \\
\hline
\end{tabular}

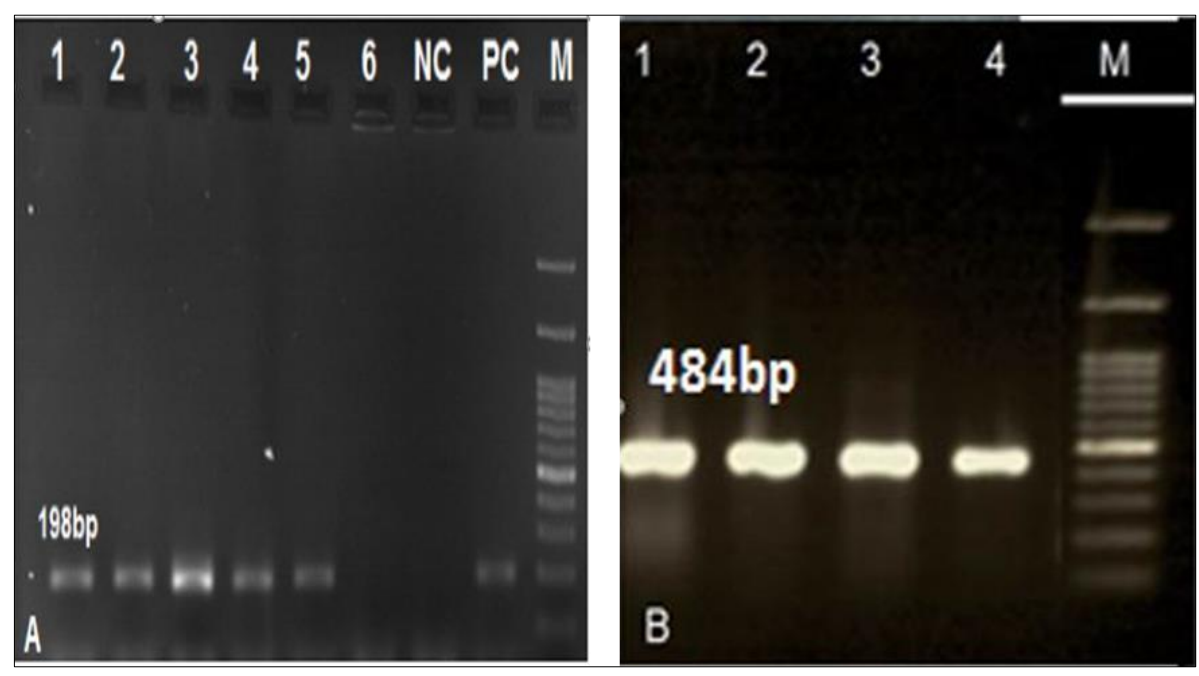

Figure 1 A blaIMP1 with 198bp size, B: blaOXA-48-like with 484bp size, M: 100bp DNA marker, PC: positive control, NC: negative control

\section{Discussion}

The opportunistic pathogen, E. Cloacae has been reported to carry carbapenemas genes worldwide [14, 15]. This study showed that 134 E. Cloacae isolates (67\%) had class I integron. In general, there is a lot of information about the prevalence of different classes of integrons in a species of Klebsiella and E. coli, but little is known about the species of Enterobacter. Studies on the prevalence of different classes of integrons and their content have different results in terms of the existence of different factors of drug resistance; In different geographical areas, the prevalence of class I integrons in gram-negative pathogens has been reported from $28.5 \%$ (8\% to $89.2 \%$ ). They reported that $34 \%$ of the Enterobacteriaceae family members were positive in terms of the presence of class I integrons [16, 17]. In a study by Ibrahim et al., in Malaysia on Enterobacteriaceae isolates, it was found that $61.4 \%$ of the isolates had class I integrons. In China, $76.3 \%$ of isolates were positive in terms of the presence of class I integrons [18]. Antibiotics are another factor involved in different statistics on the prevalence of class I integrons in different geographical areas. In this study, most isolates containing class I integron (46\%) were isolated from the ICU. The main reasons for the prevalence of resistant organisms in this ward can be the following: long-term hospitalization of patients in this ward, the severity of the 
patient's illness and the use of invasive therapeutic tools such as chips and catheters. In the present study, there was a significant relationship between resistance to carbapenems and the presence of class I integrons. Moreover, the existence of blaIMP gene was significantly higher among isolates containing class I integron. In this study, for the first time in our area, the class I integron and carbapenemases were detected in E. Cloacae. The limitations of this study included lack of gene expression and narraw resistance genes assessed.

\section{Conclusion}

The existence of class I integron was high among E. Cloacae from Baghdad city. The carriage of genes resistance to carbapenems were significantly associated to the class I integrin.

\section{Compliance with ethical standards}

\section{Acknowledgments}

To my colleagues working in laboratories inside my college (College of Biotechnology -Al-Nahrain University-BaghdadIraq) and to those who helped me collect samples and resources.

\section{Disclosure of conflict of interest}

The authors declare that they have no conflict of interests.

\section{References}

[1] Mezzatesta ML, Gona F, Stefani S. Enterobacter Cloacae complex: clinical impact and emerging antibiotic resistance. Future Microbiol. 2012; 7: 887-902.

[2] Kremer A, Hoffmann H. Prevalences of the Enterobacter Cloacae complex and its phylogenetic derivatives in the nosocomial environment. Eur J Clin Microbiol Infect Dis. 2012; 31: 2951-2955.

[3] Paauw A, Fluit AC, Verhoef J, Leverstein-van Hall MA. Enterobacter Cloacae outbreak and emergence of quinolone resistance gene in Dutch hospital. Emerg Infect Dis. 2006; 12: 807-812.

[4] Ohud M, Eman MH, Hayam SA. Detection of Salmonella strains in clinical samples from Saudi Arabia by invA and hilA polymerase chain reaction (PCR)-based assays. African J Microbiol Res. 2012; 6: 5410-5416.

[5] Croci L, Suffredini E, Cozzi L, Toti L, Ottaviani D, Pruzzo C, et al. Comparison of different biochemical and molecular methods for the identification of Vibrio parahaemolyticus. J Appl Microbiol. 2007; 102: 229-237.

[6] Vithanage NR, Yeager TR, Jadhav SR, Palombo EA, Datta N. Comparison of identification systems for psychrotrophic bacteria isolated from raw bovine milk. Int J Food Microbiol. 2014; 189: 26-38.

[7] Leite FC, Pinheiro Machado AB, Lutz L, Vieira MI, Barth AL. Molecular identification of Burkholderia cepacia complex and species distribution among cystic fibrosis patients seen at the reference center in southern Brazil. Clin Biomed Res. 2011; 31: 138-144.

[8] Davin-Regli A. Enterobacter aerogenes and Enterobacter Cloacae; versatile bacterial pathogens confronting antibiotic treatment. Frontiers in microbiology. 2015; 18(6): 392.

[9] Mezzatesta ML, Gona F, Stefani S. Enterobacter Cloacae complex: clinical impact and emerging antibiotic resistance. Future microbiology. 2012; 7(7): 887-902.

[10] Hoffmann H, Roggenkamp A. Population genetics of the nomenspecies Enterobacter Cloacae. Applied and environmental microbiology. 2003; 69(9): 5306-18.

[11] Annavajhala MK, Gomez-Simmonds A, Uhlemann AC. Multidrug-resistant Enterobacter Cloacae complex emerging as a global, diversifying threat. Frontiers in microbiology. 2019; 31(10): 44.

[12] Ghasemian A, Mobarez AM, Peerayeh SN, Abadi AT, Khodaparast S, Nojoomi. Report of plasmid-mediated colistin resistance in Klebsiella oxytoca from Iran. Reviews in Medical Microbiology. 2018; 29(2): 59-63.

[13] Ghasemian A, Mobarez AM, Peerayeh SN, Abadi AT, Khodaparast S, Mahmood SS. Expression of adhesin genes and biofilm formation among Klebsiella oxytoca clinical isolates from patients with antibiotic-associated haemorrhagic colitis. Journal of medical microbiology. 2018; 68(7): 978-85. 
[14] Cai Y, Chen C, Zhao M, Yu X, Lan K, Liao K, Guo P, Zhang W, Ma X, He Y, Zeng J. High prevalence of metallo- $\beta$ lactamase-producing Enterobacter Cloacae from three tertiary hospitals in China. Frontiers in microbiology. 2019; 9(10): 1610.

[15] Aoki K, Harada S, Yahara K, Ishii Y, Motooka D, Nakamura S, et al. Molecular characterization of IMP-1-producing Enterobacter Cloacae complex isolates in Tokyo. Antimicrob. Agents Chemother. 2018; 62: e02091-17.

[16] Izdebski R, Baraniak A, Herda M, Fiett J, Bonten MJ, Carmeli Y, et al. MLST reveals potentially high-risk international clones of Enterobacter Cloacae. J. Antimicrob. Chemother. 2015; 70: 48-56.

[17] Liu C, Qin S, Xu H, Xu L, Zhao D, Liu X, et al. New Delhi metallo-beta-lactamase 1(NDM-1), the dominant carbapenemase detected in carbapenem-resistant Enterobacter Cloacae from Henan Province, China. PLoS ONE. 2015; 10: e0135044.

[18] Yang L, Wu AW, Su DH, Lin YP, Chen DQ, Qiu YR. Resistome analysis of Enterobacter Cloacae CY01, an extensively drug-resistant strain producing VIM-1 metallo-beta-lactamase from China. Antimicrob. Agents Chemother. 2014; 58: 6328-6330. 